\title{
Evocative Communication and Hypnosis
}

\author{
Jeffrey K. Zeig, Ph.D. ; Kaloyan S. Tanev, M.D., M.P.H. ${ }^{2}$
}

1 The Milton H. Erickson Foundation, Inc. 2632 E Thomas Rd \#200, Phoenix, AZ 85016

2 Massachusetts General Hospital, Harvard Medical School, 55 Fruit Street, Boston, MA 02114

\section{ABSTRACT}

This article reviews the role of evocative communication in psychotherapy and hypnosis. In hypnosis, the goal is to elicit a change in the client's state. Hypnosis is defined in a relational context and does not require conscious awareness to have an impact. Therapists can extend their understanding of hypnotic processes to psychotherapy to elicit conceptual realizations that empower changes in states and identities. Metaphor and signification, two examples of evocative communication, are widely used in the arts to create emotional impact. The therapist's "palette of colors" includes words, gestures, tone, tempo and locus of voice, and posture. The authors contend that: a) effective hypnotherapy and psychotherapy are anchored in evocative communication; b) communication techniques can be taught and studied; c) evocative communication spurs the activation of the subconscious; and d) the subconscious can effect changes in state that can result in solutions to psychological problems. Keywords: Hypnosis, Hypnotic induction, Psychotherapy, Metaphor, Evocative, Experiential signification

\section{Introduction}

The authors' area of exploration is evocative communication. In this article we review how multiple channels of communication can be used intentionally when the goal is emotional impact. Metaphor and signification are two examples of evocative communication. Multiple-level messaging is a foundation of hypnosis.

When we, humans, communicate, we often speak to inform. But communication can also evoke emotion and/or elicit a change in state. This is "evocative communication;" it is primarily determined by inferred meaning through nonverbal and/or contextual channels.

\footnotetext{
*Correspondence: ktanev@partners.org, Massachusetts General Hospital, Harvard Medical School, 55 Fruit Street, Boston, MA 02114. Received: 14 October 2019 Accepted: 19 June 2020
}

\section{Sleep and Hypnosis Journal homepage: http://www.sleepandhypnosis.org ISSN:1302-1192 (Print) 2458-9101 (Online)}

Let us take the simple sentence, "You are here." This sentence can be turned into a question by a slight change in emphasis through inflection; it can be turned into a compliment or cutting remark. Its meaning also can change, depending on the context.

Evocative communication has a grammar that is different from communication that is meant to inform. Therapists of all disciplines, especially those practicing hypnosis, would be well served to learn that grammar. Hypnosis is, at its essence, an evocative means of communication designed to promote a change in state. It is not commonly used to offer facts.

Evocative communication is primarily designed to elicit changes in the communication partner's state by offering a concept that must be realized. Let us consider art such as painting, drama, or music. Art is crafted to evoke concepts that alter the recipient's realizations. Therapists could learn how to become evocative communicators by modeling artists, because artists traverse and explore an evocative world.

Evocative communication requires preconscious activation; the recipient responds to covert implication rather than overt meaning. The targeted response 
may happen without the recipient being aware that he or she responded, or that there was even a message relayed. For example, when we read a novel, we do not pay attention to the literary apparatus crafted by the author, such as the use of suspensive sentences or compound sentences with free modifiers. If we did, our flow of associations and imaginative involvement would be disrupted. The reader's response happens without conscious awareness of the technique used to elicit that response. And although we subconsciously respond to innuendo in common social communication, when we become aware of our response, we often resist because we want to remain in control of our responses.

Hess and Polt (Hess; \& Polt, 1960) showed participants two seemingly identical photos of the same woman and asked in which photo the woman was more attractive. A significant number voted voted for the photo in which the woman's pupils were retouched to appear slightly dilated, and thus larger. But most participants were not aware of the cue that led to their choice.

Dilated pupils are a sign of arousal. In the Renaissance, women in Italy used a belladonna plant extract to enlarge their pupils, so that possible suitors would find them more attractive. We are conditioned to respond to arousal, and many social psychology experiments demonstrate that frequently we do not realize the cues that lead us to a response (Aronson \& Bridgeman, 1979; Haney, Banks, \& Zimbardo, 1973; Milgram, 1963). If the recipient cognitively analyzes the message, it becomes informative, and may not have an evocative effect.

Evocative communication prompts implicit responsiveness and leads to a change in state, which can sometimes prompt a change in identity (For example, "I am being responsible" to "I am a responsible person').

\section{Hypnosis and Evocative Communication}

Hypnosis uses trance, a state which occurs naturally, such as when one daydreams or "gets lost" in a novel; trance could also be elicited by the hypnotherapist. Hypnosis is defined in the context of a relationship, just as love is defined in the context of a relationship. In order to elicit love, evocative communication is essential. Similarly, to elicit hypnosis, evocative communication is essential, because the goal is to elicit a change in the client's state.

Hypnosis requires the subject to realize an implicit message, which could be as simple as, "You can change your state." A necessary component of hypnosis is the response to implicit meaning. (Zeig, 2014).

There is also a temporal element to hypnosis. Trance changes over time, similar to other states such as anxiety and depression.

Clients who seek therapy are often stuck in maladaptive states such as anxiety and depression. Metaphorically speaking, it is as if the client's problematic situation is a standard car and the client is stuck in reverse. The client may be depressed or anxious; nonetheless, he or she feels constricted, uncomfortable, and frustrated. Therefore, it is the job of the therapist to help the client move into first gear. But, to move from reverse to first gear, the client must go through neutral; hypnotic induction can serve as that neutral state. Induction demonstrates to the client that his state can be changed. That change can be systemically significant; one change in state can lead to other changes, often with a "domino effect."

\section{Metaphor}

A hypnotic induction is a metaphor for changing states. It commonly involves bi-level communication, which makes it evocative. On one level, the hypnotherapistis talking to theclient about something, perhaps a walk on the beach, perhaps intense focus on an object; on another level, the hypnotherapist is suggesting that the client's state can be altered. Again, let us consider art.

Artists are masters of evocative communication, including metaphor. Shakespeare is metaphorical when he has Romeo say: "What light through yonder window breaks? It is the East and Juliet is the sun." Shakespeare uses metaphor to offer a conceptual realization, not information. If he wanted us to know specifically how Juliet is attractive and appealing, he could have written, "Juliet is beautiful, with long dark hair and...” Instead, he says Juliet is the sun, which of course should not be taken literally because a metaphor is not literal. 
A metaphor is a word or phrase that directly refers to one thing by mentioning another that is seemingly unrelated. Of course, Juliet is not the sun, but she is like the sun: an intense and alluring light; something that is imperative to life. Now "Juliet is the sun" could have many meanings, but the fact that Romeo is wild about her is indisputable. Shakespeare's metaphor is ambiguous, which is a component of evocative communication.

Metaphor is considered figurative language, and it requires the recipient of the communication to subconsciously activate to "unpack" the message. The same could be said of hypnosis; it requires that the client subconsciously work to understand the targeted implication.

Traditional hypnotists often use a scripted induction, working as if the induction is an injector and therapeutic suggestions are the medicine. They commonly use direct therapeutic suggestions, for example, "You will be comfortable in an airplane." But, being comfortable is a concept, and evocative methods are efficient in eliciting the change in states, comfort for example. An evocative principle is to create the dots, but not connect them, thereby allowing the client to evocatively realize a connection. One way a therapist can do this, is by using metaphor, another way is by using signification.

\section{Signification and Hypnosis}

Signification, which is integral to evocative communication, is a nonverbal message that relays a concept. A pointed finger is an example of signification. No words are necessary for the meaning to reach the recipient. A sound can also signify a concept. Again, the goal with evocative communication is for the recipient to have a conceptual realization, and signification offers this opportunity.

Signification is found in the arts. When Rembrandt was painting, photography did not exist. Perhaps that explains why his portraits are realistic renderings. Rembrandt successfully captured his subjects without the extensive use of signification. However, when Claude Monet was painting, photography already existed, which could explain why he used elements similar to signification. In his painting, "Water Lilies," Monet offers the viewer indications or impressions of the aquatic flower, not a realistic portrayal. Impressionism is evocative communication, because the meaning must be intuited by the viewer.

When teaching hypnosis, the authors encourage students to use signification in any stage of therapy, and especially when offering hypnosis, because a gesture or a sound can be more evocatively impactful rather than words. One's posture can also communicate a concept. For example, instead of saying, "It would be good if you learned to stand up for yourself," the therapist could stand up straight with shoulders drawn back, and say, "Learning to do this might be helpful."

During induction and hypnotherapy, the authors advise students to embody the concepts they offer, and act them out, even though the client's eyes are closed. For example, when talking to the client about taking steps toward becoming happy, the therapist could smile and move his arms in a stepwise manner. Erickson commonly smiled when offering hypnosis, indicating that he took pleasure in the client's accomplishments. These subtle evocative elements summate quickly; we know from social psychological experiments that they have an effect. See for example: Bargh, 2017. (Bargh, 2017).

\section{Implication}

Evocative communication is ambiguous; it requires the recipient of the message to adapt it to his/her own context to make sense of it. If we say to someone, "Here is a table I think you would find useful," the meaning of this statement could be determined contextually by the recipient. For example, this statement would have a different meaning to a mathematician than it would to a writer, a chef, a massage therapist, etc.

Voice emphasis or inflection is another part of evocative communication. In an induction, the therapist might say, "You can effortlessly experience comfort deeply right now." Or, "You can effortlessly experience comfort deeply right now." Or, "You can effortlessly...experience comfort...deeply right now." Although the same words are used for each statement, each can convey a slightly different meaning because of the change in emphasis. And, there can be as many variations with emphasis as there are words to a sentence. 
In the academic literature on hypnosis, the question whether direct or indirect suggestion is more effective has been the subject of long-standing debate (Lankton \& Matthews, 2010; Matthews \& Mosher, 1988). An alternative point of view is that even the most direct of suggestions in hypnosis generates evocative meaning, which depends on the therapist's extraverbal emphasis, deemphasis, the context, etc.

Among other language forms, Erickson used presuppositions, which in the field are thought of as indirection, but his communication was not designed to be indirect, or to trick a person. Erickson used presuppositions to evoke conceptual realizations that would promote more adaptive states.

T.X. Barber, one of the great researchers in the history of hypnosis, put quotation marks around the word "hypnosis" because he did not believe it was a state (Barber, 1969). But the authors believe it is more appropriate to put the word "state" in quotations, because one's state is often determined by an evocative event. Webster's definition of state is: a mode or condition of being. Science is based on facts, whereas phenomenology is based on lived experiences. When we want to relay a fact, we offer information. When we want to elicit a state that can alter phenomenology, such as love, acceptance, interest, trust, or hypnosis, then we use evocative communication.

Evocative communication is the basis of hypnosis, whether the "operator" realizes it or not. For example, a hypnotherapist normally uses a certain tone of voice and tempo in the induction, which is evocative. When a hypnotherapist changes her voice to a hypnotic tone, she communicates to the client that it is time to transition into a trance state.

Beethoven's $5^{\text {th }}$ Symphony is a perfect example of evocative communication. It opens with four notes, perhaps the most well-known in Western music. Beethoven strategically jumps into action, and the symphony offers listeners an evocative experience, which could be intuited as the triumph of hope over fate.

\section{Hypnotic Phenomena}

In traditional hypnosis, the induction is unrelated to the therapy; it usually involves focused attention and relaxation; it is only a means to an end -- to get the person into trance. After the induction, there is often a "challenge" suggestion that is based in the use of hypnotic phenomena. For example, the therapist could directly suggest: "Your arm is a steel bar and you cannot bend it." If the client reacts by displaying an unmovable arm, it indicates that her unconscious mind is responding. After the response, the hypnotist offers therapeutic suggestions.

But if a therapist wants the client to know that she (the client) is uniquely responding, hypnotic phenomena based on evocative, multilevel communication, could be used as a bridge between the induction and therapy. Erickson used hypnotic phenomena as an opportunity to be evocative and to use multilevel communication. The following is an example.

\section{Transcript of Milton Erickson}

Shortly before he died, Erickson did an induction using age regression with a woman named Sally (Zeig, 1980). The following passage follows the induction when he offered a hypnotic phenomenon with an evocative purpose.

Now I don't know where you live, but you might like to go barefoot...You might like to...sit in your swimming pool and dangle your feet in the water... and wish you could swim. [Sally slightly smiles] And would you like your favorite candy to eat right now? [Sally smiles and nods slowly; mouths "yes."] Now here it is, and now you feel it in your mouth.... and enjoy it. (Erickson pantomimes offering candy.)

The first author had the pleasure of discussing this induction in-depth with Erickson (Zeig, 1980). After viewing this segment, the first author turned off the video and asked, "Dr. Erickson, why did you use the hypnotic phenomenon of candy? Why didn't you instead suggest something else? Did you suggest candy because Sally had been regressed to a little girl, and little girls learn to not take candy from strangers?" His reply was, “Well Jeff, you didn't listen. I didn't say candy, I said favorite candy. And what stranger could possibly know what a little girl's favorite candy is?" He was presupposing that Sally would trust him by offering her a favorite candy, which she did, in fact, accept. Trust was the targeted state to be accessed evocatively by implication. 
Erickson was a precise communicator and his work with Sally exemplifies this. The first author spent a lot of time with Erickson and felt genuinely loved that someone would work so hard to communicate with him. Every word and gesture were designed to have an effect.

In the induction with Sally, Erickson first looked at the floor when he spoke. His strategic purpose of not directing his voice at her was that he wanted Sally to experience his words as coming from everywhere and nowhere in particular. He wanted her to work to internalize his words.

Erickson also says two things that are permissible for Sally to do: He first suggests that she go barefoot, and then that she put her feet in water and wish she could swim. The strategic purpose is to lead to the suggestion, "Would you like your favorite candy to eat right now?" She smiles, and he pantomimes giving it to her, then touches her hand. "Here it is. Put in your mouth and enjoy it (motivation)." He did not just apply a hypnotic phenomenon. He also strategically presented it in a series of discrete steps.

With Sally, Erickson used strategic initiatives: There was a three-step process: pace, suggest, and motivate, also known as the setup, intervention, and follow through (SIFT). Erickson often presented concepts or ideas in what could be viewed as three steps, which made his presentations more interesting and impactful. The three-step process is also used by filmmakers and musicians, Spielberg and Beethoven to name a few. Erickson could have been modeling artists; nonetheless, he was in a strategic state and his method is what naturally evolved from his state (Zeig, 2015).

The SIFT approach was an epiphany for the first author. He had been trained as a Rogerian therapist, so if his patient said, "I'm sad," He would respond in a staccato way by saying, "You do seem down." Observing Erickson changed that. Today the authors often speak to clients and students using the SIFT method, especially when the target is a change in state or a realization of a concept. Now if the client says, "I'm sad," the therapist might respond by saying, "Yes, you're here and you're sad at this moment, struggling with concerns, feeling a bit helpless. And there are actions, like empowering others, that can help you to realize that can make being here in this office effective and meaningful. And that can be done in a way that is right for you and respects your style."

\section{Evocative Communication and the Limbic System}

Evocative communication does not require conscious awareness. Animals instinctively communicate by using signification. Signification is the evolutionary basis of verbal communication. Even though humans evolved to develop the neocortex part of our brain for executive functioning and logical thinking, the foundation of our communication is still limbic. As noted, evocative communication often leads to a response without the person's conscious awareness of the cue that led to the response. For example, if someone yawns, other people tend to yawn. And if someone on the street looks skyward, others feel compelled to also look up. These are examples of evocative communication that spurs limbic reaction (Buck, 1994; Schindler, Kruse, Stark, \& Kissler, 2018).

\section{Relational States}

Hypnosis is a relational state prompted by evocative communication. The same could be said about humor. If you want to elicit a state of humor, you must use evocative communication, for example, tell a joke. Like a hypnotic induction, a joke often creates tension, which in humor, is released by laughter. In an induction, the tension is released by a suggestion and/or the target intervention. A hypnotic induction should modify tension because it can be used to increase responses that alter states. When doing inductions, Erickson would sometimes increase and decrease tension, whereas traditional hypnotherapists often perform an induction like a lullaby. Musicians strategically use tension. For example, in Beethoven's Fifth Symphony there is both consonance and dissonance, soft and hard tones.

Whereas both hypnosis and humor are relational states, there is self-hypnosis, autogenic training, relaxation training, active imagination, mindfulness, and meditation. The authors maintain that interpersonal responsiveness is central to hypnosis, so we wish there was another term for "self-hypnosis." Hypnotic induction requires a relationship because 
hypnosis necessitates an automatic response to the communication, which has a covert implied meaning. (Zeig, 2014). Humor also requires a relationship and a response. Try telling yourself a joke. It does not have the same effect as if the same joke was told to you.

\section{States: Individual, Relational, and Contextual}

Some states can be accessed without a relationship. Alterations in attention and concentration, for example, do not require a relationship. A state can be highly influenced by context. Being out in nature will more likely elicit a state of wonder and gratitude than sitting home alone. Other states are highly relational. It may be easier for someone to experience a state of faith when worshiping with others than if that person were alone.

The table below presents a partial list of primarily adaptive and primarily maladaptive relational states.

\begin{tabular}{|c|c|}
\hline \multicolumn{2}{|c|}{ RELATIONAL STATES } \\
\hline Adaptive States & Maladaptive States \\
\hline Forgiving & Unforgiving \\
\hline Vulnerable & Hardened (closed) \\
\hline Independent & Dependent \\
\hline Inspired & Uninspired \\
\hline Agreeable & Disagreeable \\
\hline Resilient & Vulnerable (easily hurt) \\
\hline Social & Withdrawn \\
\hline Generous & Miserly \\
\hline Adventurous & Inhibited \\
\hline Pursuant & Avoidant \\
\hline Altruistic & Selfish \\
\hline Considerate & Inconsiderate \\
\hline Humble & Conceited (narcissistic) \\
\hline Honest & Deceptive \\
\hline Strong & Weak \\
\hline Complimentary & Critical \\
\hline Positive & Negative \\
\hline Attuned & Not attuned \\
\hline Empathic & Uncaring \\
\hline Trusting & Suspicious \\
\hline Patient & Impatient \\
\hline Respectful & Disrespectful \\
\hline Engaged & Detached \\
\hline Diplomatic & Tactless \\
\hline Assertive & Passive \\
\hline
\end{tabular}

Partial list of primarily adaptive and primarily maladaptive relational states

\section{Automaticity and Multilevel Communication}

People commonly feel as if their problems "just happen." For example, a client may say that her dinner plate was suddenly cleared, but she does not remember eating; or a pack of cigarettes seemed to disappear, but she does not remember smoking as much as she did. Similarly, states can automatically happen. A person can move seamlessly from one relational state to another without being aware. Implicit responsiveness happens because it is part of our evolutionary design and sociobiology, and it is based in signifying communication.

Therapists have long recognized that clients often use multilevel, evocative communication, such as signification. Most commonly, therapists respond by making an interpretation of meaning. For example, if the client says he has a backache, the therapist could ask, "Do you know who is on your back?" But because clients often use multilevel, evocative communication, such as signification, therapists can respond with therapeutic evocative communication. The evocative therapist could empathically reply by making the sound, "Ouch," and rubbing his back. If, instead, the therapist wanted to be constructive, he could say, "But you want to be ___ (making an empowering gesture and sound.)

Psychological problems are not frequently based on explicit memory; instead, they most often involve emotional associations, which are part of implicit memory. Emotional associations have their neural bases in the limbic system, which includes the amygdala, hippocampus, cingulate gyrus, and the parahippocampal gyrus (Nolte, 2002). Specifically, the amygdala through its connections with other limbic structures such as the hippocampus, and with extra-limbic structures such as the hypothalamus and cerebral cortex, is involved in emotion-related aspects of learning, such as fear. To illustrate its function, when both the anterior temporal lobes including the amygdalae on both sides are destroyed, humans and animals present with the Kluver-Bucy syndrome. The Kluver-Bucy syndrome is characterized by placidity, the absence of emotional reactions; nonresponsiveness to threats, or to social gestures by other animals; and with loss of sexual discrimination (Nolte, 2002). Phylogenetically, humans have 
inherited the limbic system from our predecessors. By evolutionary design, animals instinctively respond to signification not by using the cortical area of the brain, but rather the limbic system. Although humans respond with more conscious intent than an animal, and thus activate the cortex, we too activate the limbic system of our brain in response to evocative communication. Evocative, signifying communication involves implicit responsiveness on a behavioral level; it involves the limbic system on a neural level. If a therapist wants to achieve emotional impact, he must use evocative communication which activates the limbic system and other brain areas subserving emotions.

The response to signification, demand characteristics, priming, social mimicry, and conformity are studied in the field of social psychology, and studies reveal that people respond to signifying elements (Morris, 1946).

Now let us look back at the therapist-client communication and interspace. Many therapists are taught to look only at a client's internal life when defining a problem. But most problems happen in a relational context. For example, a person who becomes depressed does so in the context of his or her relationships to a significant other, friends, family, colleagues, etc.; depression influences all these relationships, and relathionships influence the person's depression. Therefore the therapist can define the problem in its relational context, and can use these relationships to help the client reach his or her therapeutic goals. The intrapsychic and interpersonal need not be dissociated from each other; they can be viewed as complementary in defining the problem and in devising the therapeutic strategy. An example of such complementary use is the case of the "African Violet Lady," a single-visit intervention for depression by Milton H. Erickson ("The African Violet Queen," 2014).

Love is often seen as something existing soley within a person, and can be defined as a feeling of romance, protectiveness, vulnerability, attractiveness, and/or attentiveness. But like most relational states, love primarily exists in an interaction. Although the concepts of self-love and unrequited love refer to states internal to the individual, the concept of love most often refers to a relationship between people.
Therefore, when defining a state such as love, it is useful to consider the person's relationships and interaction patterns, in addition to the person's internal experience.

The first author created an acronym for a definition of love that involves a relationship with another: TOPAH, which means, "Take Obvious Pleasure in Another's Happiness." When we love someone, it pleases us to see that person happy. We want the best for that person. We do not want to see that person in pain, because if they are, it pains us. Love happens when we attune to another and feel emotionally connected. However, there is not one definition of love, and there is not one pathway to its realization. Eliciting love cannot be accomplished by using a script or following a set of stepwise instructions. Love is an amalgamation of components that can only be realized through a felt experience.

\section{Deconstructing Components}

All states, including hypnosis, are a synergistic amalgamation of components. When a therapist is doing an induction, she should understand her intent and address components of the state, rather than treat the state as if it were a global entity. States are often redintegrated by partial cues. The synergistic amalgamation of cues leads to the realization of the goal state.

Similarly, psychological problems are an amalgamation of components; treating just one component of a problem can have an adaptive, synergistic effect. (For examples of using the components of a problem in therapy see Zeig, 2018).

Let us imagine hypnosis as a prism. The prism separates light into components. The hypnotic prism is a context that defines its components. Hypnosis can be put through the prism by defining it directly or indirectly. For example, a therapist could say, "Now I'm going to do a hypnotic induction." Or, a therapist could define hypnosis indirectly, something at which Erickson excelled. He might look at the floor and say, "I'm going to remind you of something that happened a long time ago..." By changing the tone, tempo, and locus of his voice, he would indirectly communicate that it was time for hypnosis, and he would elicit the definition experientially rather than didactically. 


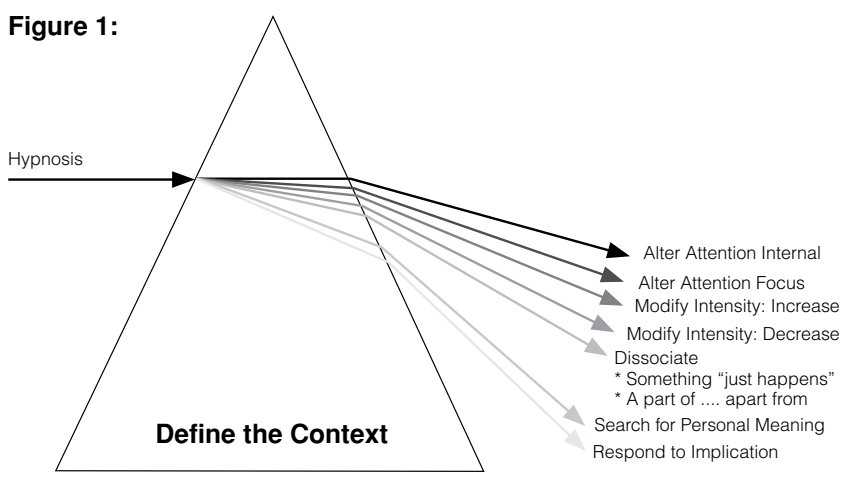

Deconstructing the concept of hypnosis into separate components analogy with light refracting through a prism

\section{The diagram on Figure 1 provides an example of using a prism:}

One component of inducing hypnosis could be merely defining the situation as hypnosis. Some clients will immediately respond to a contextual definition, reporting that they are hypnotized, whereas others need more in order to experience trance. In addition to a contextual definition, there are four other components; three of them are psychological - altered attention, modified intensity, and dissociation, and another one is relational - an alteration in response in which the hypnotized person responds to implied meaning. Each of the three psychological components and the contextual definition can be suggested directly or implicitly. If there is response to an implicit suggestion that targets one of these components, it simultaneously elicits the targeted effect and a social response to implied meaning.

\section{Figure 2:}

Hypnosis Realized Redintigrate 5 Components (Define the situation as hypnosis)

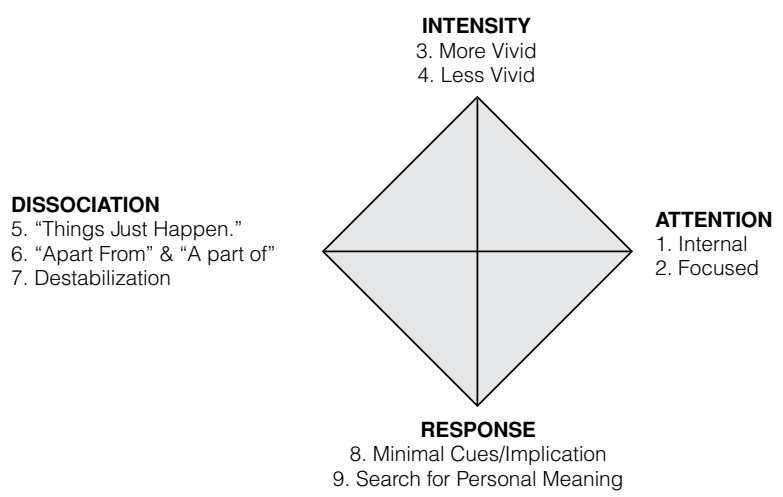

Five components of hypnosis:

1) Defining the situation as hypnosis; 2) Altered Attention;

3) Modified intensity; 4) Dissociation; 5) Response to implication
The diagram on Figure 2 presents the five components:

For example, a person could report that he is hypnotized because her attention changed. Perhaps she becomes intensely focused. Another might say that the intensity of her experience changed -- that she was extremely relaxed, or that time passed quickly, or that she did not feel her body. A client could say that she was hypnotized because she felt as if she were in two places at once (dissociation), or that her arm automatically lifted, as if she had no control of it (also dissociation). A person could say she was hypnotized because she was mildly destabilized.

Now if a client's attention changed, he could say he that was meditating, or that mindfulness caused a change in the intensity of an experience, or that his active imagination led to him to dissociate. However, the difference between hypnosis and similar change states is that hypnosis requires implicit responsiveness; the person must respond to the meaning of the communication. And when someone has adopted the state of responding to implications, the induction has achieved its goals. The therapist can then move on to the utilization phase of trance.

The authors never try to induce hypnosis. Rather, we invite the client to "play" with us as we present "toys," which are the four elements defined in the context of hypnosis. These "toys" are ways in which a client can experience hypnosis. If a person experiences some combination of the four elements in a situation defined overtly or covertly as hypnosis, that person will most likely report being hypnotized. And targeting elements allows us to tailor the induction to the unique situation of the client.

\section{Milton Erickson's Therapeutic Communication}

Milton Erickson was the first author's mentor for the last six years of his life. In the lore of hypnosis societies, a student can learn traditional hypnosis, or can learn Ericksonian methods which are considered "advanced." However, the authors believe that learning Ericksonian methods is fundamental, and that it would be beneficial for therapists to study his methods right from the beginning.

Many of Erickson's collaborators and peers felt that he was incomprehensible, and some claimed that he designed his communication to be indirect. But the 
authors maintain that especially in therapy, Erickson was commonly in the state of orienting toward, and his methods derived from his state. Erickson was a strategic signifier and he would orient his client toward a state sometimes by orienting to its components.

Erickson was a good writer, and he wrote to inform the reader. But interpersonally, he used evocative communication to elicit a change in one's state and offer conceptual realizations.

In a hypnotic induction, Erickson would not proceed with the trance utilization phase of therapy until there was a notable response to implication. Erickson knew that the induction paves the way for therapy.

Metaphorically, an induction is like planting a seed. Before planting a seed, you often need to enrich the soil. An induction is similar in that it is based in response to inuendo. The therapist needs to develop "fertile soil" before he plants a therapeutic seed. It is been said that in life one can never have enough love or money. But in the hypnotic world, the therapist can never have enough responsiveness. Erickson was a master in generating implicit responses, and his methods of orienting toward and strategically developing sequences such as pace, suggest, and motivate served him well.

\section{Essentials of Hypnosis}

In studying Erickson, the authors reach several conclusions, one being that hypnosis is based in the response to evocative, signifying communication. The content of the verbalization is not as important as the evocative elements of the therapist's communication, which engage implicit associations and activate the limbic system. In order to elicit a hypnotic state, it is necessary to use signification and/or metaphor.

Hypnosis is used to elicit conceptual realizations. It is not used to offer the client information. As opposed to medicine, which is done by an algorithmic process, hypnosis is done by heuristic principles. A psychiatrist gives medicine for depression, but a therapist treats components of depression, rather than depression as a single entity (See Zeig, 2018 for examples). The induction of hypnosis is a means of eliciting components that the client can use to indicate trance. Induction does not cause hypnosis. Let us remember that hypnosis should elicit a conceptual realization with the induction like a rollercoaster ride, not a gentle swing in a hammock. Implicit responsiveness is a key to opening the door to accessing states. Hypnosis engages the limbic system and invites a response.

\section{CONCLUSION}

Hypnosis is the progenitor of evocative approaches to psychotherapy. Once a therapist understands the processes of hypnosis, he realizes that doing psychotherapy is an evocative experience designed to elicit conceptual realizations that empower changes in states and identities.

When it comes to communication, hypnosis teaches us to use our entire "palette of colors." This includes words, gestures, tone, tempo and locus of voice, and posture. And the therapist can use these channels of communication in the subsequent therapy. Psychotherapy and hypnotherapy should be anchored in evocative signifying communication that engages the limbic system and motivates changes in the client's state that result in changing the presenting problem. 


\section{References}

Aronson, E., \& Bridgeman, D. (1979). Jigsaw groups and the desegregated classroom: In pursuit of common goals. Personality and Social Psychology Bulletin, 5(4), 438-446. https://doi. org/10.1177/014616727900500405

Barber, T. X. (1969). Hypnosis. A Scientific Approach. Van Nostrand Reinhold Company.

Bargh, J. (2017). Before You Know It: The Unconscious Reasons We Do What We Do (1st ed.). Atria Books.

Buck, R. (1994). The neuropsychology of communication: Spontaneous and symbolic aspects. Journal of Pragmatics, 22(3), 265-278. https://doi.org/10.1016/0378-2166(94)90112-o

Haney, C., Banks, C., \& Zimbardo, P. (1973). Interpersonal dynamıcs in a simulated prison. International journal of crmmology and penology, 1, 69-97.

Hess;, E. H., \& Polt, J. M. (1960). Pupil size as related to interest value of visual stimuli. Science, 131, 349-350.

Lankton, S., \& Matthews, W. J. (2010). An Ericksonian model of clinical hypnosis. In S. J.

Lynn, J. W. Rhue, \& I. Kirsch (Eds.), Handbook of Clinical Hypnosis, Second Edition (2nd ed., pp. 209-238). Retrieved from https:// www.apa.org/pubs/books/4317205

Matthews, W. J., \& Mosher, D. L. (1988). Direct and indirect hypnotic suggestion in a laboratory setting. British Journal of Experimental \& Clinical Hypnosis, 5(2), 63-71.

Milgram, S. (1963). Behavioral Study of obedience. The Journal of Abnormal and Social Psychology, 67(4), 371-378. https://doi. org/10.1037/hoo40525
Morris, C. (1946). Signs, Language and Behavior (First Edition edition). Prentice Hall.

Nolte, J. (2002). The Human Brain: An Introduction to Its Functional Anatomy (5 edition). St. Louis, Mo: Mosby.

Schindler, S., Kruse, O., Stark, R., \& Kissler, J. (2018). Attributed social context and emotional content recruit frontal and limbic brain regions during virtual feedback processing. Cognitive, Affective, \& Behavioral Neuroscience, 1-14.

The African Violet Queen: A Story of Hope, Change, Service and Possibility. (2014, February 25). Retrieved February 26, 2019, from Stories of Change and Possibility website: http:// storiesofchangeandpossibility.com/the-african-violet-queen-astory-of-hope-change-service-and-possibility/

Zeig, J. K. (Ed.). (1980). A Teaching Seminar With Milton H. Erickson (1st edition). New York: Brunner/Mazel.

Zeig, J. K. (2014). The Induction of Hypnosis: An Ericksonian Elicitation Approach (1st ed.). Phoenix, AZ: Milton H. Erickson Foundation Press.

Zeig, J. K. (2015). Psychoaerobics: An Experiential Method of Empower Therapist Excellence (1st edition). Milton H. Erickson Foundation Press.

Zeig, J. K. (2018). The Anatomy of Experiential Impact Through Ericksonian Psychotherapy: Seeing, Doing, Being (1st ed., Vols. 1-1). Retrieved from https://www.thriftbooks.com/w/ the-anatomy-of-experiential-impact-through-ericksonianpsychotherapy-seeing-doing-being/18523609/\#isbn=193224886 2\&idiq=25663025 